\title{
Production Function Analysis of Member Dairy Cooperative Society for Milch Cow in District Etawah (U.P.)
}

\author{
Dr. Ashish Chandra, Dr Arun Bhadauria
}

Asstt professor, Amity Business School, Amity University Lucknow Campus, Lucknow, U.P. India

\begin{abstract}
This study covered Cobb douglas production function, Tukey and Kramer analysis on members dairy cooperative society for milch cow in district Etawah of U.P. In study researchers have taken post- stratified into Landless, Marginal, small, medium and large herd size categories. The study effect of various factors of production in (Rs.) like Feeding cost included (dry fodder + green fodder), expenditure of concentrate included (grain + khali + mineral material and chunni / choker) and miscellaneous expenses included (labor charge and fixed cost) on milk produced by the cow of dairy cooperative society members in annual in different categories of farmers. Further, the researchers have found out the comparative analysis of all the categories of dairy cooperative society members. At last Tukey and Kramer test was applied on all the category of dairy cooperatives society members in milch cow to get into the depth of the problem under investigation. This study is helpful to find out the elasticity of different factors of milk production by means of comparative analysis in all categories of members dairy cooperative society in milch Cow by Cob douglas production function analysis.

Keywords - Elasticity of fodder, Elasticity of concentrate, Elasticity of miscellaneous, Return to scale, Classification Code: Agriculture Management.
\end{abstract}

\section{INTRODUCTION}

As per an assessment made by the Planning Commission Report-2012, the domestic demand for the milk by 2020-21 is expected to be 172.20 million tons. India would have sufficient production to meet such demand. The international body on the farm sector in its latest 'Food Outlook' report also estimates global milk production in 2020 grow by $2 \%$ to 772 million tones.

India ranks first in milk production, accounting for $18.5 \%$ of world production. India ranks first in milk production, accounting for $18.5 \%$ of world production, achieving an annual output of 146.3 million tones during 2014-15 as compared to 137.69 million tonnes during 2013-14 recording a growth of $6.26 \%$. Whereas, the Food and Agriculture Organization (FAO) has reported a $3.1 \%$ increase in world milk production from 765 million tones in 2013 to 789 million tones in 2014.

The per capita availability of milk in India has increased from 176 grams per day in 1990-91 to 322 grams per day by 2014-15. It is more than the world average of 294 grams per day during 2013. This represents a sustained growth in availability of milk and milk products for the growing population Dairying has become an important secondary source of income for millions of rural households engaged in agriculture. The success of the dairy industry has resulted from the integrated co-operative system of milk collection, transportation, processing and distribution, conversion of the same to milk powder and products, to minimize seasonal impact on suppliers and buyers, retail distribution of milk and milk products, sharing of profits with the farmer, which are ploughed back to enhance productivity and needs to be emulated by other farm produce/producers. India's milk production rise by 4\% i.e., 127.9 million tonnes in 2011-12 and per capita availability was 291 gms/day while in 2010-11 milk production was 121.8 million tones and per capita availability was 281 gms/day. * In domestic market demand of milk and dairy products is increasing very high but the production processing facilities of milk in India is not up-to the mark.

The study analyzed various factors of production in (Rs.) like Feeding cost included (dry fodder + green fodder), expenditure of Concentrate included (grain + khali + mineral material and chunni / choker) and miscellaneous expenses included (labor charge and fixed cost) on milk produced by the cow of dairy cooperative society members in annual in different categories of farmers i.e, landless, marginal, small, medium and large on the basis of land 
holding capacity. Analyses of Cobb Douglas production function, researchers find out elasticity of fodder, concentrate and miscellaneous factors of milk production. Further, the researchers have indentified percentage of data variation on different category members of dairy cooperative society. At last Tukey and Kramer test was applied on all the category of dairy cooperatives society members in milch cow to get into the depth of the problem under investigation. This study is helpful to find out the comparative analysis in all categories of members dairy cooperative society in milch Cow.

"Etawah" in Uttar Pradesh is famous for its Bhadawari breeds of buffalo and Jamunapari breed of goats. The said breed of buffalo were also known for consuming less fodder relative to production of high fat content milk. However, all the milch animals such as buffalo, cow and goats are grazed in the ravines and the forest area between Jamuna and Chambal rivers of Etawah district of U.P. The numbers of milch livestock of Etawah district during 2012 were reported as total number of female adult cows $1,10,825$ total number of adult females' buffaloes 92065 and total female adult goats were 2, 41, 61 .

The trend shows that very soon Etawah district will get an important place in the future, map of "milk Grid" of India Influenced milk yields. The test for efficiency of resource use revealed that there was inefficiency in the use concentrates. Profit maximization I equires that the marginal value product of an input be equated to the price. If this condition is fulfilled in the study area with respect to concentrates, the average milk YleLo per animal per year would increase by $73 \%$ above the current levels. An important conclusion of the study is that there could be substantial in milk output and consequently gains in farm profits if the amount of concentrates fed to the animals is increased above the cur-r-errt level s. It is recommended that:- (i ) effot'ts be intensified to educate the benefits of inct eased feeding of concentt'ates to the (i i ) animals, constraints which contribute to the unavailability of concentt'ates when farmers need them be removed, (iii) farmers be educated on how they can the excess animal feeds which is $\mathrm{p}$ r-ociuc ed the wet season to feed the animals during the (iv) be and educated on how best season, they can utilize the farm by-products while hey are of high nutrition value to feed the animals.

Prajneshu,(2008), the set of Cobb-Douglas production functions is usually fitted by first linear zing the models through logarithmic transformation and then applying the method of least squares. However, this procedure is valid by producing on an average of 2.801 lakh liters per day during 1986-87 which was increased to 3.83 lakh litres per day during 2006-07 and 5.20 lakh liters per day during 2011-12, and further increased by 6.81 lakh liters per day during 2014-15. There were 3020 cooperative milk producers- societies during 1986-87, increased to 4272 during 20011-12 and 4576 during 2014-15.

\section{REVIEW OF LITERATURE}

Murithi, Festus Meme,(2002), study was motivated by the need to find means of increasing milk supply in Kenya in order to meet an expected rise in demand. The study was concerned with the efficiency of resource use in smallholder milk production. The major objective of the study was to determine whether tnere are possibilities of increasing milk production through re-allocation of the resources used in milk production The problems encountered by farmers involved in milk production were also examined. The data used in the study were collected from 60 smallholders who are members of five Dairy Co-operative Societies which are affiliated to the Meru Central Farmers Co-operative Union. A Cobb-Douglas milk production function was fitted using the inputs used in milk production. The results showed that concentrates significantly

only when the underlying assumption of multiplicative error-terms is justified. Unfortunately, this assumption is rarely satisfied in practice and accordingly, the results obtained are of doubtful nature. Further, nonlinear estimation procedures generally yield parameter estimates exhibiting extremely high correlations, implying thereby that the parameters are not estimated independently. In this paper, use of expected-value parameters has been highlighted and the advantages of their use have also been discussed. Finally, the developed methodology has been illustrated by applying it to the wheat yield time-series data of Punjab.

Venkatesh P. and Sangeetha V.,(2011), a study was conducted to examine the cost structure and resource use efficiency of dairy farms in the Madurai district of Tamil Nadu. The dairy farmers were selected by using multi stage random sampling technique. Tabular analysis and CobbDouglas production function were used in this study. Total costs per lactation per animal estimated were of the order of Rs.12776.09, Rs 11791.20 and Rs.12079.28 and returns per rupee of investment $0.78,1.08$ and 0.95 respectively on small, large and pooled farms. Feed cost was the higher input cost in dairy farming (61.6\%). The cost of production milk per litre was less in case of large farms (Rs. 4.62) 
compared to small farms (Rs. 5.39). Results indicated the inverse relationship with the size and the herd of the total costs, due to economies of scale. Functional analysis showed barring human labour on small farms all the selected input variables such as green fodder, dry fodder, concentrates and health care were positive and significant impact on the production of milk indicating the potentiality of their further use.

Meena G. L. et.al.,(2012), study was undertaken in Alwar District of Rajasthan with the objectives to examine the input-output relationships and assess the resource use efficiency in milk production. The study covered 75 cooperative member milk producers and 75 non-cooperative member milk producers. The results of Cobb-Douglas production function revealed that concentrate had positive and significant influence on returns from buffalo milk across all the household categories for both the member and non-member groups. Green fodder and dry fodder were also influenced the returns from milk significantly across all the household categories for both the member and non-member groups with the sole exception of large category of nonmember group. $\mathrm{D}_{1}$ (winter) and $\mathrm{D}_{2}$ (Rainy) dummy variables were found to be positive and statistically significant. The results of Chow's test clearly revealed that the production functions between member and non-member groups differed significantly. The results of the resource use efficiency revealed that green fodder was over-utilized in small and medium categories for both the member and nonmember groups, dry fodder was over-utilized by medium category of member group, concentrate was over-utilized by only medium category of member group and by small \& medium categories of non-member group while it was under-utilized by large category of non-member group and labour was over-utilized by only small category of member group.

Singh, K. M. et. al., (2012), Dairy farming has emerged as an important source of livelihood, particularly on small holder households. The efficient management of dairy cooperative system has facilitated milk production and marketing in Bihar. An attempt was made to analyze the milk contribution to dairy co-operative, producers' share in consumer rupee and cost of milk production in Bihar. Per litre cost of milk production varied from Rs. 10.12 for crossbred cows to 13.90 and Rs. 13.57 for buffalo and local cows, respectively, which are higher than price paid by cooperatives for standard milk (fat-6\% and SNF-21\%). Herd size and type of milch animal along with parity had significant influence on cost of milk production. Production cost is likely to decrease with increase in size of unit and in production of crossbred cows in herd. More than two-third of milk produced by co-operative members is marketed through dairy co-operatives in Bihar. The producers' share in consumer rupee is about $58 \%$ for all categories of herd since all are marketing their milk through co-operatives only. Dairy farmers should also be advised for meeting the requirements of feed by providing desired nutrients through feeding of green fodder which not only reduces intake of concentrates but also helps in reducing the cost of production. Treatment of dry fodder with urea helps in improving its nutritive value, and such technologies may be popularized to make feeding balanced and cost effective.

Crispen D. et.al.(2014), study looked at the operational challenges to smallholder dairy farming. Focus in this study was specifically on Mayfield Small Scale Dairy Settlement Scheme in Chipinge District of Zimbabwe. The study made use of interviews, questionnaires, observations and project reports in collecting both qualitative and quantitative research data. Semi-structured questionnaires were administered to a sample of 75 farmers randomly selected from a total population of 345 family farmers on the dairy settlement scheme. In addition, 24 key informants were conveniently sampled for interviews from among the scheme's management, farmer committee leaders and extension staff. The study noted that while dairy operations at the settlement scheme managed to yield notable benefits to the farmers, there were a number of operational challenges working against full commercialization of production at the scheme. These problems bordered on lack of access to capital, poor production and marketing infrastructure, weak extension support, insecure land tenure, lack of farmer involvement in production planning and poor social relations between farmers and management on the one hand and among the farmers themselves, on the other hand. The study recommends that these problems be addressed, not only at Mayfield Dairy Settlement Scheme, but also elsewhere, if smallholder dairy operations are to serve as real tools for rural transformation in Zimbabwe and other less developed countries.

Carla, D. (2014), studied that women play an important role in the economic and social development of societies, but they are often denied equal opportunities because of socially embedded gender inequalities. This research looks at the potential of dairy cooperatives for women ${ }^{\text {ee }} \mathrm{s}$ empowerment in South India. Dairy production is of great importance for rural economy in India and women contribute significantly to this activity. The Women Empowerment in Agriculture Index developed by the 
International Food Policy Research Institute was adapted and applied as a research tool. Using a snowball sampling technique, structured interviews were conducted with women involved in four different dairy cooperatives (29) and women selling at the private market (29). The results of the study indicate that there are economic benefits for women participating in dairy cooperatives. However, the outcomes for women s empowerment are ambiguous. Only in some domains women in dairy cooperatives rank their empowerment status higher compared to non-members. The results point to the fact that economic gains provided by cooperatives may not always lead to greater empowerment for women. Moreover, the analysis indicates that women in mixed-gender cooperatives experience greater decisionmaking power compared to women in single-gender cooperatives. This study suggests that additional measures supporting women ${ }^{e s}$ s role in dairy cooperatives and a more participatory management are required in order to enhance gender equality.

\section{RESEARCH METHDOLOGY}

District Etawah milk producers' cooperative union was purposively selected from the state of Uttar Pradesh. Exhaustive lists of all the milk producers' cooperative societies in Etawah district milk producers' cooperative union were prepared. Researchers have selected randomly 150 non member of dairy cooperative society \& 150 members of dairy cooperative society from 10 Villages of 2 blocks selected in district Etawah. All the milk producing household members and non members were classified into five categories, viz., Landless, Marginal, Small, Medium and Large farmers on the basis of land holding capability. Thus, in all, 300 households were interviewed during the year 2008-09. The primary data were collected to help of well structured pre-tested schedule by the personal inquiry method. The data collected were subjected to tabular analysis in order to study the comparative economics of milk production. Cobb-Douglas type Production Functional analysis was applied on cow milk production with three variables like-fodder, concentrate and miscellaneous of different categories landless, marginal, small, medium and large member farmers of dairy cooperative society.

The study effect of various factors of production in (Rs.) in case of milk cooperative societies members in annual in different categories. $\quad y=a x_{1}^{b_{1}} x_{2}^{b_{2}} x_{3}^{b_{3}}$ ...... (1)

$\log \mathrm{y}=\log \mathrm{a}+\mathrm{b}_{1} \log \mathrm{X}_{1}+\mathrm{b}_{2} \log \mathrm{X}_{2}+\mathrm{b}_{3} \log \mathrm{X}_{3}$

Where

$$
\begin{aligned}
& \mathrm{Y} \quad=\quad \text { Production of milk in (Rs.) } \\
& \mathrm{X}_{1}=\text { Feeding cost included (dry fodder }+ \\
& \text { green fodder) } \\
& \mathrm{X}_{2}=\text { Expenditure of Concentrate included } \\
& \text { (grain }+ \text { khali }+ \text { mineral material and } \\
& \text { chunni / choker) } \\
& \mathrm{X}_{3}=\text { Miscellaneous expenses included a } \\
& \text { labor charge and fixed cost. } \\
& \mathrm{b}_{\mathrm{i}} \quad=\quad \text { Respective elasticity's of milk } \\
& \text { production } \\
& \mathrm{a}=\text { constant }
\end{aligned}
$$

Having estimated the cost of milk production, it is desirable to ascertain the reliability of these fodder costs, concentrate

\begin{tabular}{|c|c|c|c|c|}
\hline Category of farmers & Elasticity Fodder & $\begin{array}{l}\text { Elasticity of } \\
\text { Concentrate }\end{array}$ & $\begin{array}{c}\text { Elasticity of } \\
\text { Miscellaneous }\end{array}$ & $R^{2}$ value \\
\hline Land less & $3.600 *$ & 2.471 & 1.073 & \multirow[t]{3}{*}{78.81} \\
\hline "t" test value & 2.14 & 0.27 & 0.02 & \\
\hline S.E value & $(0.2598)$ & $(1.4449)$ & $(1.5081)$ & \\
\hline Marginal & $23.84^{*}$ & $-3.558 *$ & 1.0769 & \multirow[t]{3}{*}{84.74} \\
\hline "t" test value & 11.53 & -2.48 & 0.19 & \\
\hline S.E value & $(0.1195)$ & $(0.22275)$ & $(0.16856)$ & \\
\hline Small & 18.6680* & $150.1412 *$ & -328.62 & 91.51 \\
\hline
\end{tabular}
cost and miscellaneous expanses estimates. The most commonly used " $\mathrm{t}$ " test was applied to ascertain whether the cost of milk is significantly different from zero or not at some specified probability level.

" $\mathrm{t}$ " cal $=\mathrm{b}_{\mathrm{j}} / \mathrm{standard}$ error of $\mathrm{b}_{\mathrm{j} . \text {. }}$

If calculated " $\mathrm{t}$ " value is greater than the table value of " $t$ " at a specified probability level and " $\mathrm{n}-\mathrm{k}-1$ " degree freedom, bj is said to be statistically significant.

\section{REASEARCH AND FINDINGS}

Table.1: COBB DOUGLAS PRODUCTION FUNCTION ANALYSIS OF MEMBERS DAIRY COOPERATIVE SOCIETY (COW) 


\begin{tabular}{|c|c|c|c|c|}
\hline "t” test value & 6.25 & 1.87 & -2.18 & \\
\hline S.E value & $(0.203263)$ & $(1.161996)$ & $(1.153742)$ & \\
\hline Medium "t" test value & 3.910 & 1.035 & 1.037 & \\
\hline & 1.45 & 0.07 & 0.07 & \\
\hline S.E value & $(0.4070)$ & $(0.2165)$ & $(0.2280)$ & \\
\hline Large & $11.708^{*}$ & -12752.6 & 9223.16 & \multirow{2}{*}{87.18} \\
\hline "t" test value & 2.67 & -0.91 & 0.93 & \\
\hline S.E value & $(0.40066)$ & $(4.5120)$ & $(4.2695)$ & \\
\hline
\end{tabular}

The analysis has revealed that Landless member farmers of dairy cooperative society failed to give sufficient Concentrate and Miscellaneous inputs to the milch cow but Fodder could provide significant effect result on cow milk production and further medium category only fodder and concentrate could provide a significant effect on milk production and next small member farmers were doing same as marginal farmers and in large member farmers, only fodder could provide a significant effect on milk production of cow but in medium members farmers of dairy cooperative society none of the variables like Fodder, Concentrate and miscellaneous inputs could provide a significant effect result on cow milk production. The analysis further revealed that 78.81, 84.74, 91.51, 43.44 and $87.18 \%$ of the variation was explained by three input variables in land less, marginal, small, medium and large member farmers of dairy cooperative society respectively. Moreover, all the variables in this category remained the same.

\section{Summary of all categories of Members of Dairy Cooperative Society for Milch Cow} One-way Analysis of Price by Category

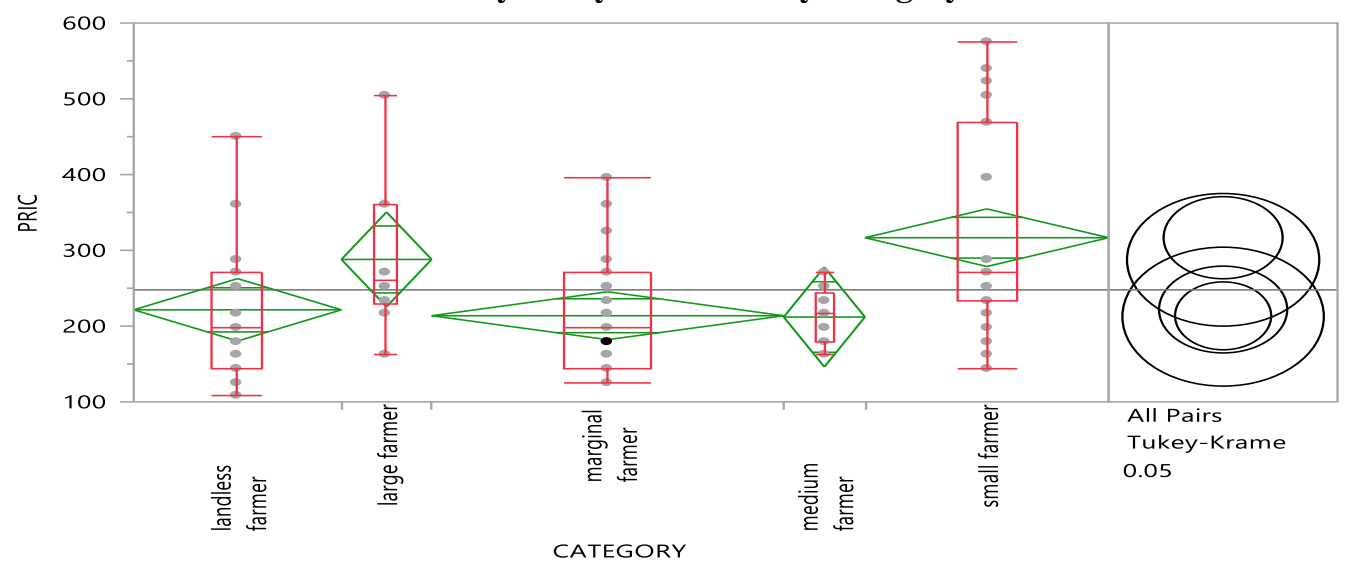

Table.2: Tukey-Kramer Analysis

Level

small farmer

large farmer

landless farmer

marginal farmer

medium farmer
Mean

316.66667

$\begin{array}{lll}\text { A } & \text { B } & 288.00000\end{array}$

221.47826

213.69231

A $\quad$ B 212.00000 
Table.3: Ordered Differences Report

Level

small farmer

small farmer

small farmer

large farmer

large farmer

large farmer

small farmer

landless farmer

landless farmer

marginal farmer
- Level

medium farmer

marginal farmer

landless farmer

medium farmer

marginal farmer

landless farmer

large farmer

medium farmer

marginal farmer

medium farmer
Difference

104.6667

102.9744

95.1884

76.0000

74.3077

66.5217

28.6667

9.4783

7.7860

1.6923

\section{Summary of all categories of Members of Dairy Cooperative Society for Milch Cow:}

The analysis are revealed that in table no $2 \& 3$, mean of small farmers was observed Rs. 316.667 followed by large farmers Rs. 288.00, Landless Rs. 221.48, Marginal farmers Rs. 213.69 and least for Medium farmers Rs. 212.00. This indicated fact that small farmer interestedness in milch animals especially in cow is the highest.

$\begin{array}{rrrr}\text { Std Err Dif } & \text { Lower CL } & \text { Upper CL } & \text { p-Value } \\ 38.33406 & -1.775 & 211.1086 & 0.0563 \\ 24.93415 & 33.740 & 172.2088 & 0.0007^{*} \\ 28.26024 & 16.718 & 173.6584 & 0.0092^{*} \\ 45.76066 & -51.063 & 203.0633 & 0.4626 \\ 35.30226 & -23.716 & 172.3312 & 0.2259 \\ 37.72505 & -38.229 & 171.2726 & 0.4005 \\ 36.86852 & -73.706 & 131.0392 & 0.9365 \\ 39.15854 & -99.253 & 118.2095 & 0.9992 \\ 26.18402 & -64.919 & 80.4909 & 0.9983 \\ 36.83017 & -100.574 & 103.9584 & 1.0000\end{array}$

Tukey test was applied to get into the depth of the problem under investigation. This indicated that there is no significant statistical difference between small large and medium member farmers for milch cow. Further, there is no difference between Large, Landless Marginal and farmers. Further indicated the fact that $\mathrm{P}$ value for Small and Large farmer, Small and Landless were observed significant at 5 $\%$ level of Probability (.0007 and .0092) respectively.

Table.4: Return to Scale for the Dairy Cooperative Society Members (Cow):

\begin{tabular}{|l|l|l|l|l|l|r|}
\hline S.N. & Category & \multicolumn{1}{|c|}{$\boldsymbol{\beta}_{\mathbf{1}}$} & \multicolumn{1}{|c|}{$\boldsymbol{\beta}_{\mathbf{2}}$} & \multicolumn{1}{|c|}{$\boldsymbol{\beta}_{\mathbf{3}}$} & $\begin{array}{l}\text { Total } \\
\boldsymbol{\beta}_{\mathbf{1}+\boldsymbol{\beta}_{\mathbf{2}+} \boldsymbol{\beta}_{3}}\end{array}$ & $\begin{array}{l}\text { Return to } \\
\text { Scale } \geq \mathbf{1}\end{array}$ \\
\hline 1 & Landless & 3.600 & 2.471 & 1.073 & 7.144 & $\geq \mathbf{1}$ \\
\hline 2 & Marginal & 23.84 & -3.558 & 1.0769 & 21.358 & $\geq \mathbf{1}$ \\
\hline 3 & Small & 18.6680 & 150.1412 & -328.62 & -159.810 & $\leq 1$ \\
\hline 4 & Medium & 3.910 & 1.035 & 1.037 & 5.982 & $\leq 1$ \\
\hline 5 & Large & 11.708 & -12752.6 & 9223.16 & -3.17 .76 & $\leq 1$ \\
\hline
\end{tabular}

$\boldsymbol{\beta}_{1}=\quad$ Elasticity of Fodder

$\boldsymbol{\beta}_{2}=\quad$ Elasticity of Concentrate

$\boldsymbol{\beta}_{\mathbf{3}}=\quad$ Elasticity of Miscellaneous expanses

The above table no 4 reveal that Elasticity of milk production for all the five categories of member of dairy cooperative society in cow namely Landless, marginal, small, medium and large farmers. The last column indicates their economies of scale. Their respective value were observed 7.144, 21.3589, -159.8108, 5.982 and -3.17 .76$ respectively. Out of these five categories, namely small and large farmers were observed had decreasing return to scale with a value of -159.8108 and -3.17 .76 respectively.

The remaining three categories, i.e., landless, marginal and medium exhibited increasing return to scale with the value of 7.144, 21.3589 and 5.982 respectively. The analysis further reveals that return to scale was the highest for marginal farmers followed by landless and medium member farmers of dairy cooperative society.

It will here mention that the policy makers and planners engaged in dairy enterprise should concentrate all the above two categories small and large member farmers in case of a cow should be given proper attention to enhance milk production in the area under jurisdiction.

\section{CONCLUSION}

The results of the study revealed that Landless member farmers of dairy cooperative society failed to give sufficient Concentrate and Miscellaneous inputs to the milch cow but Fodder could provide significant effect result on cow milk production and further medium category only fodder and concentrate could provide a significant effect on milk 
production and next small farmers were doing same as marginal farmers and in large member farmers, only fodder could provide a significant effect on milk production of cow but in medium members farmers, none of the variables like Fodder, Concentrate and miscellaneous inputs could provide a significant effect result on cow milk production. Analysis of Tukey test indicated that there is no significant statistical difference between small, large and medium member farmers and no difference between Large, Landless and Marginal farmers.

Analysis of Elasticity of milk production for all the five categories of member of dairy cooperative society in cow namely Landless, marginal, small, medium and large farmers. Out of these five categories that return to scale was the highest for marginal farmers followed by landless and medium member farmers.

It will here mention that the policy makers and planners engaged in dairy enterprise should concentrate all the above two categories small and large member farmers in case of a cow should be given proper attention to enhance milk production in the area under jurisdiction.

\section{REFERENCES}

[1] http://planningcommission.nic.in/reports/genrep/ar_en g1112.pdf

[2] Murithi, Festus Meme.2002 Efficiency of resource use in smallholder milk production: the case of Meru central dairy farmers, Kenya, http://erepository.uonbi.ac.ke:8080/xmlui/handle/1234 56789/21808

[3] Meena G. L.et.al, 2012. Milk Production Function And Resource Use Efficiency In Alwar District of Rajasthan, INTERNATIONAL JOURNAL OF SCIENTIFIC \& TECHNOLOGY RESEARCH VOLUME 1, ISSUE 8, 115-119

[4] Prajneshu.2008. Fitting of Cobb-Douglas Production Functions: Revisited, Agricultural Economics Research Review, Vol. 21 , 289-292.

[5] Venkatesh P. and V. Sangeetha.2011. Milk Production and Resource Use Efficiency in Madurai District of Tamil Nadu: An Economic Analysis, Journal of Community Mobilization and Sustainable Development Vol. 6(1), 025-030.

[6] Deoghare, P.R. and N.K. Bhattacharya. 1994. Economics of buffalo milk production in Mathura district of Uttar Pradesh. Indian Journal of Animal Science, 64(12): 1368- 1372
[7] Baruah, D.K.; A.B. Sarker and N.N. Bora. 1996. A study of economics of milk production in Assam. Indian Journal of Dairy Science, 49(1): 17-22.

[8] Economic survey 2015-16: http://www.news18.com/news/business/economicsurvey-2015-16-india-ranks-first-in-milk-productionaccounting-for-18-5-per-cent-of-world-production1208209.html 11:37 AM 23rd Nov, 2016. 